\title{
TPH1 gene polymorphism rs211105 influences serotonin and tryptophan hydroxylase 1 concentrations in acute pancreatitis patients
}

\section{Jadwiga Snarska}

Department of General Surgery, Faculty of Medical Sciences, University of Warmia and Mazury

\section{Ewa Fiedorowicz}

Department of Biochemistry, Faculty of Biology and Biotechnology, University of Warmia and Mazury

\section{Dominika Rozmus}

Department of Biochemistry, Faculty of Biology and Biotechnology, University of Warmia and Mazury

\section{Konrad Wroński}

General and Colorectal Surgery Clinic, University Clinical Hospital of the Military Medical Academy -

Central Veterans Hospital in Lodz

\section{Maria Latacz}

Department of Biochemistry, Faculty of Biology and Biotechnology, University of Warmia and Mazury

\section{Natalia Kordulewska}

Department of Biochemistry, Faculty of Biology and Biotechnology, University of Warmia and Mazury Janusz Płomiński

Department and Clinic of Orthopaedics and Traumatology, Collegium Medicum, University of Warmia and Mazury

\section{Roman Grzybowski}

Department and Clinic of Orthopaedics and Traumatology, Collegium Medicum, University of Warmia and Mazury

\section{Huub F.J. Savelkoul}

Cell Biology and Immunology Group, Department of Animal Sciences, Wageningen University and Research

\section{Elżbieta Kostyra}

Department of Biochemistry, Faculty of Biology and Biotechnology, University of Warmia and Mazury Anna Cieślińska ( $\nabla$ anna.cieslinska@uwm.edu.pl)

Department of Biochemistry, Faculty of Biology and Biotechnology, University of Warmia and Mazury

\section{Research Article}

Keywords: AP, polymorphism, acute pancreatitis, rs211105, TPH1, tryptophan hydroxylase 1 
Posted Date: October 21st, 2021

DOI: https://doi.org/10.21203/rs.3.rs-567244/v2

License: (c) (i) This work is licensed under a Creative Commons Attribution 4.0 International License. Read Full License 


\section{Abstract \\ Background}

The role of serotonin and its metabolic pathway in proper functioning of the pancreas has not been thoroughly investigated yet in acute pancreatitis (AP) patients. Tryptophan hydroxylase (TPH) as the ratelimiting enzyme of serotonin synthesis has been considered for possible associations in various diseases. Single-nucleotide polymorphisms (SNPs) in TPH genes have been already described in associations with psychiatric and digestive system disorders. This study aimed to explore the association of a rs211105 (T/G) polymorphism in TPH1 gene with tryptophan hydroxylase 1 concentrations in blood serum in a population of acute pancreatitis patients, and to investigate this association with acute pancreatitis susceptibility.

\section{Results}

Our data showed an association between the presence of the $T$ allele at the position rs211105 (OR $=2.47$, $95 \% \mathrm{Cl}: 0.94-6.50, p=0.06)$ under conditions of a decreased AP incidence. For TT and GT genotypes in the control group, the lowest concentration of TPH was associated with higher serotonin levels (TT: Rs $=-0.415, p=0.0018 ; G T: R s=-0,457, p=0.0066)$, while for the AP group the highest levels of TPH among the TT genotype were associated with lower levels of serotonin (TT: Rs=-0.749, $p<0.0001$, and in the GG genotype higher levels of TPH were associated with higher levels of serotonin (GG: Rs=-0.738, $p=0.037$ ).

\section{Conclusions}

Here, a new insight in the potential role of a selected genetic factor in pancreatitis development was shown. Not only the metabolic pathway of serotonin, but also factors affecting serotonin synthesis may be interesting and important points in acute pancreatitis.

\section{Introduction}

Ischaemia, bile duct obstruction, activation of pancreatic protease as well as pro-inflammatory cytokines are important components in the etiopathogenesis of acute pancreatitis (AP) [1, 2]. AP may have an unpredictable course. Therefore, there is an urgent need for determination of the prognostic symptoms that would enable to identify patients at high risk of severe course [3, 4]. Till now, more severe AP has been associated with older age, obesity, pancreatic necrosis, fluid collection, organ failure and some genetic factors [5]. The role of serotonin and its metabolic pathway in the proper functioning of the pancreas has not been thoroughly investigated yet with respect to AP.

Serotonin (5-HT, 5-hydroxytryptamine) is a monoamine neurotransmitter, synthesized in serotonergic neurons of the central nervous system (CNS), in enterochromaffin cells (EC) present in the 
gastrointestinal epithelium [6] and also, immune system cells as macrophages, and T cells [7]. However, it is known that the brain-derived serotonin provides only about $5 \%$ of total body serotonin, while $95 \%$ of serotonin is produced in the peripheral organs, mostly in the gut. These findings triggered further research on serotonin function in multiple physiology aspects [8].

The 2-step enzymatic synthesis pathway starts from dietary L-tryptophan conversion into 5-hydroxy-Ltryptophan (5-HTP) and then to 5-HT by the activity of two enzymes: tryptophan hydroxylase (TPH) and ubiquitous aromatic L-amino acid decarboxylase (AADC), respectively (Figure 1). 5-HT is degraded into 5hydrosyindoleacetic acid by monoamine oxidase $A(5-\mathrm{HIAA})[7,9]$.

Serotonin regulates emotional expression and social behaviour, but also proliferation of immune system cells, muscle and epithelial cells, and neurons $[6,10,11]$. It is also a chemotactic molecule for such cells as eosinophils, dendritic cells and mast cells [7]. It has been proven that the intracellular content of serotonin correlates positively with the insulin secretion rate, and TPH1-deficient mice showed the development of a mild form of diabetes as a result of impaired insulin secretion in the pancreas [12]. Almaca et al. [13] found that serotonin is a paracrine signal released by human pancreatic $\beta$-cells and regulating glucagon secretion. The effect of serotonin deficiency, the lack of its transporters, receptors or enzymes of the serotonin pathway are implicated in many diseases, including depression, numerous mood swings, emotional instability, schizophrenia and other neurological disorders, and irritable bowel syndrome [14-22].

Because the serotonin concentration is regulated by the rate-limiting enzyme TPH, this TPH has been considered for possible associations with suicidal behaviour [19, 20, 23, 24], irritable bowel syndrome [18], or depression [25]. Presently, two forms of TPH were identified (TPH1 and TPH2), with TPH2 being expressed mainly in the brain, while TPH1 is expressed in brain and EC cells in the gut [18].

The human TPH1 gene has been cloned and mapped to chromosome 11p15.3-14 (Gene ID: 7166); it has 11 exons $[19,24]$ and consists of 444 amino acids [18].Single-nucleotide polymorphisms (SNPs) have been described in genes coding for type one and type two tryptophan hydroxylases in association with psychiatric disorders and suicidal behaviour [26-29]. There are also a few studies investigating the role of the rs211105 polymorphism in diarrhoea-predominant irritable bowel syndrome, and the digestive system $[18,21,22]$. However, to the best of our knowledge, there are no published data on TPH1 polymorphism rs211105 in correlation to serotonin hydroxylase 1 activity or serotonin concentrations in blood serum.

In the present study, we investigated the association of the TPH1 gene polymorphism rs211105 (T/G) with acute pancreatitis and tryptophan hydroxylase 1 concentrations in circulation. Due to the fact that tryptophan hydroxylase 1 is also expressed in $\beta$-cells of the pancreas [6], we predict its role in proper pancreas functioning.

\section{Materials And Methods}




\subsection{Ethics and general information}

Specialists recruited all 198 participants either at the Department of General Surgery and Oncology of the Warmia and Mazury University Hospital in Olsztyn or at the Clinical Department of Trauma-Orthopedic Surgery and Spine Surgery of the Provincial Specialist Hospital in Olsztyn in 2014-2020. All participants were treated according to the Patient Right Protection Act of our institution and international guidelines, and the Local Bioethics Committee approved our study $(13 / 2016 ; 51 / 2019)$.

Peripheral blood samples $(5-10 \mathrm{ml})$ was collected into a tube containing EDTA, were collected from each patient by the medical staff, and all biological material was immediately transported to the laboratory and directly used in analysis or stored at $-80^{\circ} \mathrm{C}$.

\subsection{Controls and AP group characteristic}

Our study included 198 individuals (all Caucasian): 107 patients diagnosed with AP (19 females and 88 males; mean age ranging from 28 to 76 years; average 52.4 ) and 91 healthy people ( 25 females and 66 males; mean age ranging from 23 to 68 years; average 44.2). This is therefore a cross-sectional study.

Patients were admitted to the hospital 8-36 hours after the onset of AP symptoms (pain, vomiting, emetic reflex). Comorbidity of chronic circulatory system, liver, kidney or lung diseases caused exclusions from the study. Blood samples were collected from the forearm vein for the panel of biochemical tests twice upon arrival at the hospital and 48 hours after admission. Within 2 days, each patient had computed tomography (CT) with contrast performed to detect fluid collections, the extent of inflammation or necrotic changes. APACHE-II (Acute Physiology And Chronic Health Evaluation II) scores were calculated using data from the first $24 \mathrm{~h}$ after admission to assess patients' condition. Predicting acute pancreatitis severity and potential complications were based on imaging scales performed 3-4 days after the onset of symptoms, then after 10-12 days treatment.

For AP group, primarily patients with alcohol-related acute pancreatitis were selected for the study. $75 \%$ of AP cases met the DSM IV criteria for alcohol dependence, and $25 \%$ - incidental cause of inflammation. Both groups presented no inflammatory disease or other infection symptoms, no urogenital tract or kidney failure. This was confirmed by laboratory tests, and all required data was collected from their medical records and/or a filled-in questionnaire. The control group included individuals after control visit at hospital, and volunteers. Both groups were matched in age, and gender ratio. Table 1 presents the characteristics of both groups.

\subsection{Polymorphism rs 211105 in TPH1 gene in healthy and AP patients}


DNA was isolated from peripheral blood using GeneJET ${ }^{T M}$ Whole Blood Genomic DNA Purification Mini Kit (Thermo Scientific, Waltham, USA) according to the manufacturer's instructions. Polymorphism rs211105 was assessed by polymerase chain reaction - restriction fragment length polymorphism (PCR-RFLP) according to the method described by Shiotani et al. [21] with own modification. Primers for PCR reaction had the following sequence:

TPH1HAF forward primer: caaaagcagaataaagatgcaca and

TPH1HAR reverse primer: acctacagggtgagggaagg.

The program in a thermocycler consisted of and initial denaturation at $94^{\circ} \mathrm{C}$ for $3 \mathrm{~min}$, a proper denaturation at $94^{\circ} \mathrm{C}$ for $30 \mathrm{~s}$, attaching the primers at a temperature of $61^{\circ} \mathrm{C}$ for $30 \mathrm{~s}$, synthesis at $72^{\circ} \mathrm{C}$ for $30 \mathrm{~s}$, and final synthesis at $72^{\circ} \mathrm{C}$ for $5 \mathrm{~min}$. The number of cycles was 40 , after which cooling was performed at $4^{\circ} \mathrm{C}$. There was $25 \mu \mathrm{l}$ of the mixture of DreamTaq ${ }^{\mathrm{TM}}$ Green Master Mix (Thermo Scientific, Waltham, USA), specific primers, the DNA matrix and molecularly pure water (Sigma-Aldrich, Saint Louise, USA). The yield and specificity of PCR products were evaluated after electrophoresis in $1.5 \%$ agarose gel (Promega, Madison, USA) and stained with GelGreen (Biotium, Fremont, USA). Next, FastDigest ${ }^{\circledR}$ BsuRI (HaellI) (Thermo Scientific, Waltham, USA) enzyme was added to the TPH1 rs211105 PCR products and then digested according to manufacturer's instruction. For genotyping, a 2.5\% agarose gel was used (Figure 1). To confirm proper genotyping, 30 randomly chosen samples was genotyped one more time after proper genotyping. PCR-RFLP products were: TT (324 bp), GG (75, 249 bp), and GT (324, 249, 75 bp).

\subsection{Tryptophan hydroxylase 1 concentration}

TPH1 concentration has been determined in plasma using Human Tryptophan 5-hydroxylase 1 ELISA kit according to the manufacturer's instruction (Wuhan ElAab Science Co., China). The analysis was performed in duplicate at $37^{\circ} \mathrm{C}$ with gentle shaking $(250 \mathrm{rpm})$ in a microplate incubator (SkyLine ELMI Shaker DTS-4, Riga, Lithuania).

In brief, TPH 1 content was measured in the following order: $100 \mu \mathrm{L}$ of Samples, Blank, and Standards in range of concentration $0.312-20 \mathrm{ng} / \mathrm{mL}$ were added into microtiter strips and incubated for 2 hours. After removal of the liquids, $100 \mu \mathrm{L}$ of Detection reagent $\mathrm{A}$ working solution was added. Incubation was carried out for 1 hour, after that the microplate was rinsed three times with Wash Buffer, and $100 \mu$ l of the Detection reagent B working solution was added. After a 1-hour incubation, rinsing the microplate with Wash Buff-er was performed as previously, and $100 \mu \mathrm{L}$ of Substrate Solution was added to each well. After a 15-minute incubation, $50 \mu \mathrm{L}$ of Stop Solution was pipetted to the microplate. The absorbance was measured at a wavelength of $\lambda=450 \mathrm{~nm}$ using an ELISA reader (BiogenetAsys UVM 340, Cambridge, UK). 


\subsection{Serotonin concentration}

The analysis was performed in duplicate using the Serotonin ELISA kit according to the manufacturer's instruction (LDN, Labor Diagnostika NORD, Nordhorn, Germany), and described before by Cieślińska et al. [30]. All steps of the ELISA were carried out at RT (room temperature) with gentle shaking ( $250 \mathrm{rpm}$ ) in microplate incubator (SkyLine ELMI Shaker DTS-4, Riga, Lithuania). Samples were acylated before analysis as follows: $25 \mu \mathrm{L}$ of serum, standards or controls was mixed with $500 \mu \mathrm{L}$ of acylation buffer and $25 \mu \mathrm{L}$ of acylation reagent provided with the kit. The mixtures were incubated for 15 minutes at RT. Serotonin content was measured as follows: a standard curve in concentration $10.2-2500 \mathrm{ng} / \mathrm{mL}$, controls and serum samples were pipetted into serotonin microtiter strips. Then, $100 \mu$ of the serotoninspecific antiserum preparation was added into all wells and incubation was carried out for 30 minutes. Plate was washed three times with Wash Buffer and $100 \mu$ of the conjugate was added. After 15 minutes of incubation, $100 \mu \mathrm{L}$ of substrate was pipetted. A 15-minute incubation was repeated and $100 \mu \mathrm{L}$ of stop solution was added. The absorbance was measured at a wavelength of $\lambda=450 \mathrm{~nm}$ using an ELISA reader (BiogenetAsys UVM 340, Cambridge, UK).

\subsection{Statistical analysis}

The frequency distribution of common risk factors for AP are presented as the mean. The genotype distribution among subjects was analysed for Hardy-Weinberg equilibrium (HWE) using the chi-square test, and genotype and SNP allele frequencies were compared in AP patients and control groups by Fisher's test. Odds ratios (ORs) and 95\% confidence intervals (Cls) were calculated using logistic regression analysis and used to compare both allele frequencies in controls and AP patients, and allele frequencies between females and males. The risk of AP development was estimated via wild-type genotype and wild/mutant versus the mutant-type genotypes. Serotonin and tryptophan hydroxylase 1 concentration results were used to determine the distribution of variables, and are presented as a mean \pm standard error. The mean values in Control and AP groups were compared using ANOVA and Student's ttest. One-way analysis of variance was performed for multiple comparisons between groups, and Tukey's honestly significant difference test was used to conduct post-hoc analysis. Spearman's rank correlation coefficient analysis was used to estimate the relationship between analysed parameters. Statistical analysis was calculated using Statistica 13.1 (TIBCO Software Inc., Paolo Alto, CA, USA) and GraphPad Prism 6 software (GraphPad Software Inc., San Diego, CA, USA), with $\leq 0.01$ P-value considered statistically significant.

\section{Results}

\subsection{Polymorphism rs 211105 in the TPH1 gene}

At the rs 211105 polymorphic site the frequency of alleles $\mathrm{T}$ and $\mathrm{G}$ were determined in healthy individuals and in those diagnosed with AP in our study population. Concentrations of serotonin and TPH were used 
to determine the normality of distribution ( $W>0.90 ; p<0.05$ for the study and control group).

The three genotypes (TT, GT and GG) were identified in the whole study population (Control and AP). Of the total 198 participants, 108 had genotype TT, 79 had GT and 11 had GG. The observed genotype frequencies at rs211105 polymorphic site of TPH1 gene in Controls $(\chi 2=0.73, p=0.39)$ and AP patients $(x 2=0.11, p=0.74)$ conformed to the Hardy-Weinberg equilibrium. This suggests no unexpected population stratification and no sampling bias.

Table 2 shows the genotype distributions, allele frequencies and associations between genotype at the rs211105 polymorphic site and the associated AP incidence. We determined an association between the presence of the $\mathrm{T}$ allele at the position rs211105 (OR $=2.47,95 \% \mathrm{Cl}: 0.94-6.50, \mathrm{p}=0.06)$ of the tryptophan hydroxylase 1 gene under conditions of a decreased AP incidence. We also noted that in AP group in comparison to Control group genotype $G G$ at the position rs 211105 is more frequent than $\mathrm{GT}$ (OR=2.01, 95\%Cl: 0.49-8.16, $p=0.32)$ and TT (OR=2.67, 95\%Cl: 0.67-10.59, $\mathrm{p}=0.16)$.

\subsection{Tryptophan hydroxylase 1 concentration in serum}

The average TPH1 concentration in the Control group was $12.8 \mathrm{ng} / \mathrm{ml}(\mathrm{SDE}=0.09)$, and in the AP group $16.5 \mathrm{ng} / \mathrm{ml}(\mathrm{SDE}=0.41)$ with a statistically significant difference $(\mathrm{p}<0.0001)$. Figure 2 presents the tryptophan hydroxylase 1 concentrations according to TPH1 rs211105 (T/G) genotype in both control and AP groups. The largest difference was found between the control and AP groups with the GG genotype $(12.7 \mathrm{ng} / \mathrm{ml}, \mathrm{SDE}=1.97)$. Tryptophan hydroxylase $1(\mathrm{TPH})$ concentrations in serum $(\mathrm{ng} / \mathrm{ml})$ in correlation to genotype are presented in Figure 3.

Spearman's rank correlation coefficient with TPH, serotonin concentrations and the respective genotypes in both control and AP groups showed that among the control group lower levels of TPH correlated to higher serotonin level (TT: $R s=-0.42 ; p=0.002$ and $G T: R s=-0.46 ; p=0.0066)$. Among AP group, Rs values were even higher (TT: Rs=-0.75, $p<0.0001 ; G G: R s=-0.74 ; p=0.04)$. The scatter plots of tryptophan hydroxylase 1 versus serotonin for the control group are presented in Figure 4, and for AP group in Figure 5. The scatter plots of serotonin with the different genotypes of rs 211105 in TPH 1 gene are shown in Figure 6 for the control group, and in Figure 7 for the AP group.

\section{Discussion}

Pancreatic $\beta$ cells are the main cell type regulating glucose and lipid homeostasis by the action of their insulin production which is controlled by nutrients (mainly glucose level), the nervous system, and the presence of other hormones, including melatonin, estrogen, leptin, growth hormone, and glucagon like peptide-1 [8]. There are several studies showing that pancreatic $\beta$ cells are also capable of serotonin production, and contain the enzymes required for serotonin synthesis, including TPH1 and TPH2 [8, 31, 32]. 
Combined genetic, metabolic and environmental factors contribute to the development and reoccurrence of acute and chronic pancreatitis [33]. To the best of our knowledge, this is the first examination and association of TPH1 gene polymorphism rs211105 and serotonin and tryptophan hydroxylase concentrations in patients diagnosed with acute pancreatitis.

The present study involved 198 individuals: 91 Controls and 107 AP patients. The results of laboratory parameters determined prior to analysis are presented in Table 1. Higher levels than accepted reference points for bilirubin, ALT, and AST were determined in the AP patients $(1.9 \mathrm{mg} / \mathrm{dL}, 155.7 \mathrm{IU} / \mathrm{L}$ and 155.2 IU/L, respectively). AP patients also had increased amylase activity, significantly higher lipase activity indicating pancreatic dysfunction. Their additional high $\mathrm{p}<0.001 \mathrm{CRP}$ level demonstrates an ongoing and chronic inflammation.

It has been known that serotonin has an important role in the development of experimental colitis pathogenesis and causes the secretion of proinflammatory mediators in the immune system. The regulation of 5-HT and 5-TH expressing cells is closely correlated with level of inflammation, which is characteristic in many diseases of the digestive system and various types of cancer [7, 34]. In energy metabolism, crucial roles are played by insulin, glucagon, and serotonin, whose concentration is regulated by the amount of glucose in the human body [31]. Here, we have shown a statistically significant correlation between the genotype of TPH gene and levels of serotonin.

The serotonin level in the control group was higher than in the AP group. The inverse correlation was related to the concentration of TPH, which was higher in the AP group compared to the control group. . It is worth emphasizing that with a lower concentration of TPH in the control, a high concentration of serotonin is still maintained, while in the AP group - despite a high concentration of TPH, serotonin levels are lower (Figure 2).

In the AP group, the TT genotype was linked to a higher TPH concentration and to the lowest serotonin levels (Rs=-0.75, $p<0.0001)$ in comparison to the control group, where the TT and GT genotype subgroups had a less strong correlation between serotonin and TPH levels. Only in the AP group of patients with GG genotype, serotonin concentration is on average higher than in the control. It has been known that the intracellular content of serotonin correlates positively with insulin secretion, which is the main factor conditioning normal glycemia [12]. Thus, we anticipate that low level of serotonin in patients with acute pancreatitis could possibly result in disruption of the synthesis of insulin, which resulted in a pathological high and sustained glucose concentration. This mechanism is consistent with the glucose concentration of the participants, where the statistically higher glucose level was related to the AP group $(p>0.05)$ as presented in Table 1.

TPH is closely related to serotonin synthesis, what has been described by many researchers [7, 34]. The inhibition of serotonin production using a specific inhibitor of TPH1 decreases the severity of trinitrobenzene sulfonic acid-induced colitis in mice, indicating that the enzymatic regulation of HT-5 synthesis may influence on the development of improved therapeutic strategies in inflammatory disorders [35]. In our study, serotonin concentration was negatively correlated with the TPH1 
concentration. Additionally, in AP patients with the TT genotype their higher TPH levels were negatively associated with serotonin concentration in comparison to controls. Thus, we showed that despite the high TPH1 concentration in the AP group, these patients had a lower serotonin concentration compared to control (Figure 2). It is suggested that our results are in conflict with the widely accepted mechanism that the synthesis of serotonin from tryptophan is enzymatically regulated by tryptophan hydroxylase in a positive correlation. However, it should be noted that our research included the analysis of the concentration TPH 1, and not its activity. Presumably, a high concentration of enzyme is not always correlated with high catalytic activity, which we described in our previous studies on the role of dipeptidyl peptidase-4 (DPPIV; EC 3.4.14.5) in autism spectrum disorders [36].

Our current results determined the relationship between serotonin and TPH-1 levels with genetic factors, including the polymorphism rs211105 in the TPH1 gene in healthy and AP patients. Table 2 shows distribution of genotypes and alleles frequencies. Our data show that three genotypes (TT, GT and GG) could be identified in both groups, with the TT genotype being predominant among all 198 participants.

We have determined that genotype GG at the position rs211105 in AP group is more frequent than GT and TT in comparison to Control group. In this study, we have also found an association between the presence of the T allele at position rs 211105 of the tryptophan hydroxylase 1 gene under conditions of a decreased AP incidence. Thus, the difference in both, TPH1 concentration and polymorphism rs 211105 in $\mathrm{TPH} 1$ gene may indicate a putative role of this enzyme in the availability of serotonin in the human body and thereby a probable impact on the development of diseases associated with glucose metabolism. This issue is highlighted by Katsumata et al. [22], by showing that the group of patients with diarrhoea predominant irritable bowel syndrome showed a significant correlation between the TPH1 rs211105 T/T genotype and their lower scores for physical and mental health, and higher scores for indigestion and diarrhoea. The frequencies of the TT/GT/GG genotypes were: $48 / 13 / 1$ ( 0.88 for $T$ and 0.12 for $G$ alleles), and 46/18/0 ( 0.86 for $T$ and 0.14 for $G$ alleles) for diarrhoea-predominant irritable bowel syndrome patients and controls, respectively. These presented frequency results are also similar to Gizatullin et al. [25], who showed a rs 211105 frequency of the T allele of 0.75 (G 0.25$)$ in the control group and 0.78 in major depression patients ( $\mathrm{G}$ 0.22), and also Andreou et al. [26] in healthy volunteers - with a 0.23 frequency for the $G$ allele. An important aspect is the influence of alcohol consumption on the development of acute pancreatitis. It is indicated that this factor is responsible for approximately $17-40 \%$ of the causes of AP $[37,38]$. It was also shown that one of the known SNPs in the TPH1 gene (rs1800532) is a potential biomarker for bipolar disorder and alcohol-dependence risk in the Caucasian population [39]. In our study, we did not take into account the relationship between the presence of the rs211105 polymorphism in the TPH1 gene and its relationship with alcoholism, because of conflicting data in the literature on selected polymorphisms in the TPH1 gene and its association with alcoholism [40]. In our previous research (unpublished data), we also did not find a relationship between the occurrence of alcoholism and the rs 211105 polymorphism, however, due to the small study group (30 individuals), these data were not included in the current publication, and were used for additional analysis when selecting the control group. 
We have made every effort to obtain fair and unbiased research. Nevertheless, we are aware of some limitations that may have occurred in the planning of this study. The following aspects should be mentioned: (I) lack of information about alcohol consumption by individuals in the control group, (II) limited number of participants in the study, (III) no follow-up monitoring of the health of participants after leaving the hospital, (IV) bias towards males in alcohol consumption in both groups. Further studies should take these considerations into account.

\section{Conclusions}

The aetiology and the course of AP are still insufficiently examined. Here, a new insight on the potential role of a serotonin-related genetic factor in pancreatitis development is described. Factors affecting serotonin synthesis may be an interesting and important consideration in acute pancreatitis. The present research focuses on an important disease from the point of epidemiology, which requires novel and fast diagnostics that is extremely important due to the prevention or alleviation of symptoms of this devastating disease. Undoubtedly, early diagnostics of acute pancreatitis combined with minimizing the adverse effects of malfunctioning pathways by choosing the right diet is a significant challenge for nutrigenomics. Therefore, the research carried out on the correlation between polymorphisms in genes and their influence on the action of TPH1 enzyme on the body, blend into the contemporary nutrigenomics trend and emphasize the role of biochemical individuality in the creation of the basis of nutrition and personalized medicine.

\section{Declarations}

Ethics approval and consent to participate: The study was conducted according to the guidelines of the Declaration of Helsinki, and approved by the Bioethics Commission at the University of Warmia and Mazury (no. 13/2016; 51/2019). An informed consent was obtained from all participants. The raw data did not contain any personal identifying information that can be linked to particular individuals, and was anonymised before its use.

Consent for publication: Not applicable.

Availability of data and materials: The datasets used and/or analysed during the current study are available from the corresponding author (Anna Cieślińska, e-mail: anna.cieslinska@uwm.edu.pl) on reasonable request.

Competing interests: All authors declare that they don't have any competing financial or non-financial interest.

Funding: This research received no external funding.

Authors' contributions: J.S.: study conception, data collection, drafting, review and editing of the manuscript, funding acquisition. E.F.: data collection, drafting, laboratory testing, review and editing of the 
manuscript. A.C.: data collection, analysis and interpretation, laboratory testing, drafting, review and editing of the manuscript. ML, D.R., and H.J.S: study conception and design, review and editing of the manuscript. N.K, R.G. and K.W.: data collection. J.P. and E.K. : study conception and design. All authors read and approved the final manuscript.

Acknowledgements: The authors sincerely thank all the patients who participated in this study.

Correspondence to: anna.cieslinska@uwm.edu.pl

\section{References}

1. Weiss FU, Simon P, Mayerle J, Kraft M, Lerch MM. Germline Mutations and Gene Polymorphism Associated With Human Pancreatitis. Endocrinology and Metabolism Clinics. 2006;35:289-302.

2. Nieminen A, Maksimow M, Mentula P, Kyhälä L, Kylänpää L, Puolakkainen P, et al. Circulating cytokines in predicting development of severe acute pancreatitis. Crit Care. 2014;18:R104.

3. Wojtuń S, Gil J, Błaszak A. [Dietary treatment in acute pancreatitis]. Pol Merkur Lekarski. 2007;22:469-73.

4. Lankisch PG, Apte M, Banks PA. Acute pancreatitis. Lancet. 2015;386:85-96.

5. Yadav D, Vege SS, Chari ST. Epidemiology of Pancreatitis. GI Epidemiology: Diseases and Clinical Methodology: Second Edition. 2014;:306-12.

6. Banskota S, Ghia J-E, Khan WI. Serotonin in the gut: Blessing or a curse. Biochimie. 2019;161:56-64.

7. Manocha M, Khan WI. Serotonin and GI Disorders: An Update on Clinical and Experimental Studies: Clinical and Translational Gastroenterology. 2012;3:e13.

8. El-Merahbi R, Löffler M, Mayer A, Sumara G. The roles of peripheral serotonin in metabolic homeostasis. FEBS Letters. 2015;589:1728-34.

9. Amireault P, Sibon D, Côté F. Life without peripheral serotonin: insights from tryptophan hydroxylase 1 knockout mice reveal the existence of paracrine/autocrine serotonergic networks. ACS Chem Neurosci. 2013;4:64-71.

10. Kistner-Griffin E, Brune CW, Davis LK, Sutcliffe JS, Cox NJ, Cook EH. Parent-of-origin effects of the serotonin transporter gene associated with autism. Am J Med Genet. 2011;156:139-44.

11. Jaiswal P, Mohanakumar KP, Rajamma U. Serotonin mediated immunoregulation and neural functions: Complicity in the aetiology of autism spectrum disorders. Neurosci Biobehav Rev. 2015;55:413-31.

12. Paulmann N, Grohmann M, Voigt J-P, Bert B, Vowinckel J, Bader M, et al. Intracellular serotonin modulates insulin secretion from pancreatic beta-cells by protein serotonylation. PLoS Biol. 2009;7:e1000229.

13. Almaça J, Molina J, Menegaz D, Pronin AN, Tamayo A, Slepak V, et al. Human Beta Cells Produce and Release Serotonin to Inhibit Glucagon Secretion from Alpha Cells. Cell Rep. 2016;17:3281-91. 
14. Serretti A, Drago A, De Ronchi D. HTR2A gene variants and psychiatric disorders: a review of current literature and selection of SNPs for future studies. Curr Med Chem. 2007;14:2053-69.

15. Brune CW, Kim S-J, Salt J, Leventhal BL, Lord C, Cook EH. 5-HTTLPR Genotype-Specific Phenotype in Children and Adolescents With Autism. Am J Psychiatry. 2006;163:2148-56.

16. Cho IH, Yoo HJ, Park M, Lee YS, Kim SA. Family-based association study of 5-HTTLPR and the 5HT2A receptor gene polymorphisms with autism spectrum disorder in Korean trios. Brain Res. 2007;1139:34-41.

17. Veenstra-VanderWeele J, Kim S-J, Lord C, Courchesne R, Akshoomoff N, Leventhal BL, et al. Transmission disequilibrium studies of the serotonin 5-HT2A receptor gene (HTR2A) in autism. Am J Med Genet. 2002;114:277-83.

18. Jun S-E, Kohen R, Cain KC, Jarrett ME, Heitkemper MM. TPH gene polymorphisms are associated with disease perception and quality of life in women with irritable bowel syndrome. Biol Res Nurs. 2014;16:95-104.

19. López-Narváez ML, Tovilla-Zárate CA, González-Castro TB, Juárez-Rojop I, Pool-García S, Genis A, et al. Association analysis of TPH-1 and TPH-2 genes with suicidal behavior in patients with attempted suicide in Mexican population. Comprehensive Psychiatry. 2015;61:72-7.

20. Beden O, Senol E, Atay S, Ak H, Altintoprak AE, Kiyan GS, et al. TPH1 A218 allele is associated with suicidal behavior in Turkish population. Legal Medicine. 2016;21:15-8.

21. Shiotani A, Kusunoki H, Ishii M, Imamura $H$, Manabe N, Kamada T, et al. Pilot study of Biomarkers for predicting effectiveness of ramosetron in diarrhea-predominant irritable bowel syndrome: expression of S100A10 and polymorphisms of TPH1. Neurogastroenterol Motil. 2015;27:82-91.

22. Katsumata R, Shiotani A, Murao T, Ishii M, Fujita M, Matsumoto H, et al. The TPH1 rs211105 gene polymorphism affects abdominal symptoms and quality of life of diarrhea-predominant irritable bowel syndrome. J Clin Biochem Nutr. 2018;62:270-6.

23. Antypa N, Serretti A, Rujescu D. Serotonergic genes and suicide: a systematic review. Eur Neuropsychopharmacol. 2013;23:1125-42.

24. González-Castro TB, Juárez-Rojop I, López-Narváez ML, Tovilla-Zárate CA. Association of TPH-1 and TPH-2 gene polymorphisms with suicidal behavior: a systematic review and meta-analysis. BMC Psychiatry. 2014;14:196.

25. Gizatullin R, Zaboli G, Jönsson EG, Åsberg M, Leopardi R. Haplotype Analysis Reveals Tryptophan Hydroxylase (TPH) 1 Gene Variants Associated with Major Depression. Biological Psychiatry. 2006;59:295-300.

26. Andreou D, Saetre P, Werge T, Andreassen OA, Agartz I, Sedvall GC, et al. Tryptophan hydroxylase gene 1 (TPH1) variants associated with cerebrospinal fluid 5-hydroxyindole acetic acid and homovanillic acid concentrations in healthy volunteers. Psychiatry Research. 2010;180:63-7.

27. Wilson ST, Stanley B, Brent DA, Oquendo MA, Huang Y, Haghighi F, et al. Interaction between Tryptophan Hydroxylase I (TPH1) Polymorphisms and Childhood Abuse is Associated with Increased Risk for Borderline Personality Disorder in Adulthood. Psychiatr Genet. 2012;22:15-24. 
28. Nielsen DA, Deng H, Patriquin MA, Harding MJ, Oldham J, Salas R, et al. Association of TPH1 and serotonin transporter genotypes with treatment response for suicidal ideation: a preliminary study. Eur Arch Psychiatry Clin Neurosci. 2020;270:633-42.

29. Pan Y-F, Zhang J-Y, Qiu H-M, Yu P-P, Liu Z-Z, Liu B, et al. Association of polymorphisms in HTR2A, TPH1, and TPH2 genes with attempted suicide in rural China. Psychiatric Genetics. 2019;29:1.

30. Cieślinska, A, Fiedorowicz E, Jarmolowska B, Kordulewska N, Kostyra E, Moszynska M, et al. Polymorphisms rs6313 and rs6314 in serotonin receptor gene (HTR2A) and serotonin concentration in autistic children. Neuropsychiatry (London). 2019;9(1), 2021-2028

31. Ohta Y, Kosaka Y, Kishimoto N, Wang J, Smith SB, Honig G, et al. Convergence of the Insulin and Serotonin Programs in the Pancreatic -Cell. Diabetes. 2011;60:3208-16.

32. Ohara-Imaizumi M, Kim H, Yoshida M, Fujiwara T, Aoyagi K, Toyofuku Y, et al. Serotonin regulates glucose-stimulated insulin secretion from pancreatic $\beta$ cells during pregnancy. PNAS. 2013;110:19420-5.

33. Whitcomb DC. Genetic Risk Factors for Pancreatic Disorders. Gastroenterology. 2013;144:1292-302.

34. Lanser L, Kink P, Egger EM, Willenbacher W, Fuchs D, Weiss G and Kurz K (2020). InflammationInduced Tryptophan Breakdown is Related With Anemia, Fatigue, and Depression in Cancer. Front. Immunol. 2020; 11:249.

35. Margolis KG, Stevanovic KD, Yang QM, Li Z, Mazo R, Gershon MD. An Inhibitor of Tryptophan Hydroxylase Successfully Ameliorates TNBS-Induced Colitis. Gastroenterology. 2011;140:S-478.

36. Jarmołowska B, Bukało M, Fiedorowicz E, Cieślińska A, Kordulewska NK, Moszyńska M, et al. Role of Milk-Derived Opioid Peptides and Proline Dipeptidyl Peptidase-4 in Autism Spectrum Disorders. Nutrients. 2019;11:87.

37. Gullo L, Migliori M, Oláh A, Farkas G, Levy P, Arvanitakis C, et al. Acute pancreatitis in five European countries: etiology and mortality. Pancreas. 2002; 24(3), 223-227.

38. Gislason H, Horn A, Hoem D, Andrén-Sandberg Å, Imsland AK, Søreide O, Viste A. Acute pancreatitis in Bergen, Norway: a study on incidence, etiology and severity. Scandinavian Journal of Surgery. 2004; 93(1), 29-33.

39. Chen D, Liu F, Yang C, Liang X, Shang Q, He W, Wang Z. Association between the TPH1 A218C polymorphism and risk of mood disorders and alcohol dependence: evidence from the current studies. Journal of affective disorders. 2012; 138(1-2), 27-33.

40. Mokrović G, Matošić A, Hranilović D, Štefulj J, Novokmet M, Orešković D, Čičin-Šain, L. Alcohol dependence and polymorphisms of serotonin-related genes: association studies. Collegium Antropologicum. 2008; 32(1), 127-131.

\section{Tables}

Table 1. Distribution of selected characteristics in acute pancreatitis patients and healthy Control group 


\begin{tabular}{c|c|c|c}
\hline Characteristic & Controls & AP \\
& $\mathrm{n}=91$ & $p$ \\
\hline Age (years) & $44.2( \pm 10.2)$ & $52.4( \pm 13.3)$ & 0.5 \\
Body mass (kg) & $70.1( \pm 12.3)$ & $75.6( \pm 11.8)$ & 0.6 \\
Amylase activity in serum (IU/L) & $79.2 .( \pm 24.7)$ & $1647.5( \pm 636.5)$ & $<0.001$ \\
Lipase (IU/L) & $114.7( \pm 40.4)$ & $1446.7( \pm 814.6)$ & $<0.001$ \\
Bilirubin (mg/dL) & $0.6( \pm 0.21)$ & $1.9( \pm 0.87)$ & 0.05 \\
Glucose (mg/dL) & $90.2( \pm 8.4)$. & $127.4( \pm 33.9)$ & 0.05 \\
AST (IU/L) & $37.2( \pm 6.4)$ & $155.2( \pm 71.6)$ & $<0.001$ \\
ALT (IU/L) & $26.2( \pm 2.1)$ & $155.7( \pm 30.2)$ & $<0.001$ \\
CRP (mg/dL) & $0.31( \pm 0.6)$ & $4.4( \pm 1.4)$ & $<0.001$ \\
\hline Female (\%) & 27.4 & 17.7 & \\
APACHE II scale & n.a. & $4.4( \pm 1.4)$ & \\
\hline
\end{tabular}

P-values were determined by Tukey's test.

Table 2. Genotype and allele frequencies of rs211105 in TPH1 gene polymorphism in studied groups and T-allele acute pancreatitis association.

\begin{tabular}{ccccc}
\hline Genotype/Allele & $\begin{array}{c}\text { AP } \\
\text { n (\%) }\end{array}$ & $\begin{array}{c}\text { Control } \\
\mathbf{n}(\%)\end{array}$ & OR (95\% CI) Control vs AP & p-Value \\
\hline TT & $54(50.5)$ & $54(59.3)$ & $1.32(0.74-2.37)$ & 0.34 \\
GT & $45(42.1)$ & $34(37.4)$ & $2.67(0.67-10.59)$ & 0.16 \\
GG & $8(7.5)$ & $3(3.3)$ & & \\
\hline G & $61(29)$ & $40(22)$ & & \\
T & $153(71)$ & $142(78)$ & & \\
\hline Control vs AP & & & & \\
TT+ GT & & & & \\
vs GG & &
\end{tabular}

CI: confidence interval, OR: odds ratio; AP: acute pancreatitis patients

Figures 


\section{L-tryptophan}
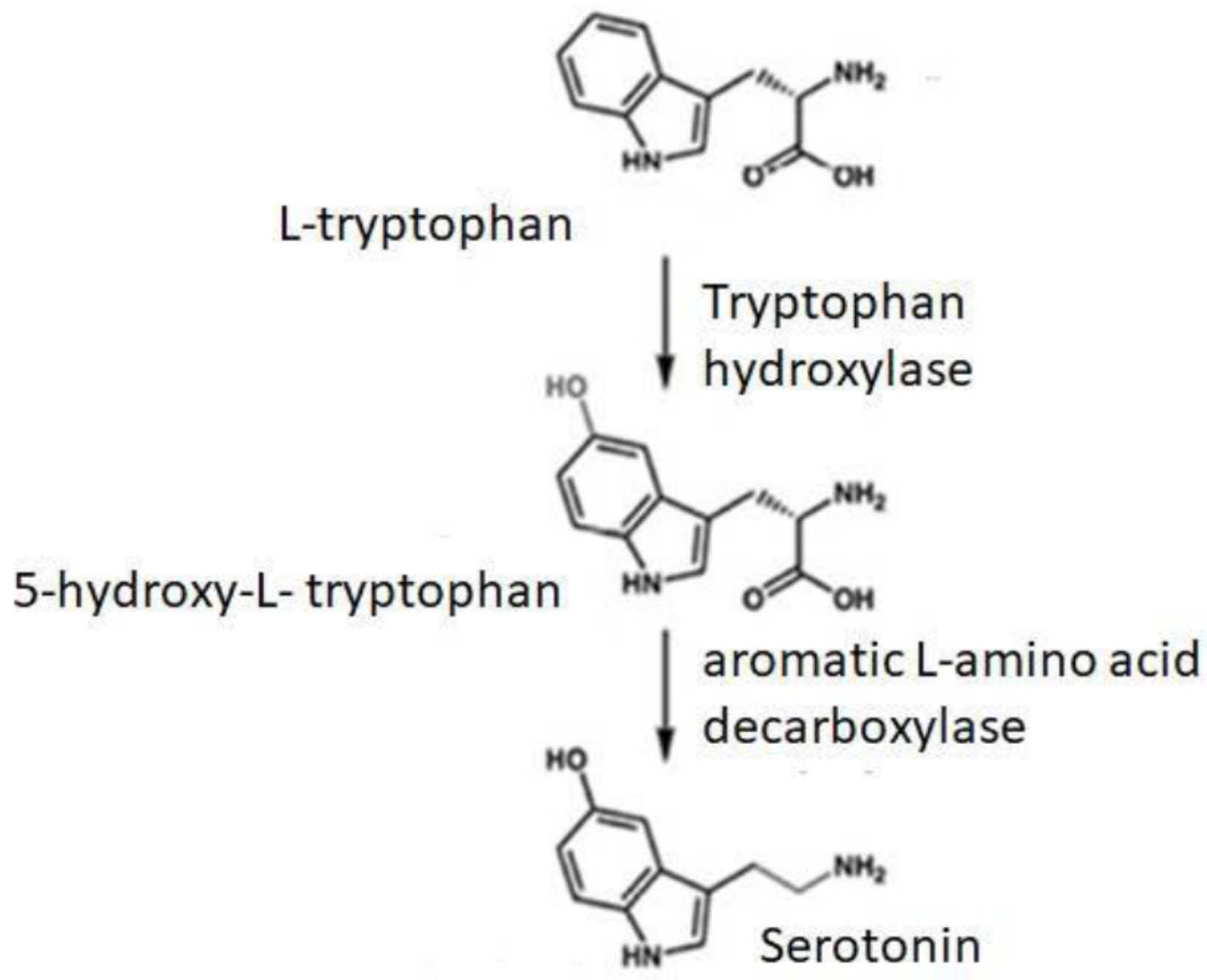

Figure 1

Scheme of serotonin synthesis from L-tryptophane (based on El-Merahbi et al. [8] modified)
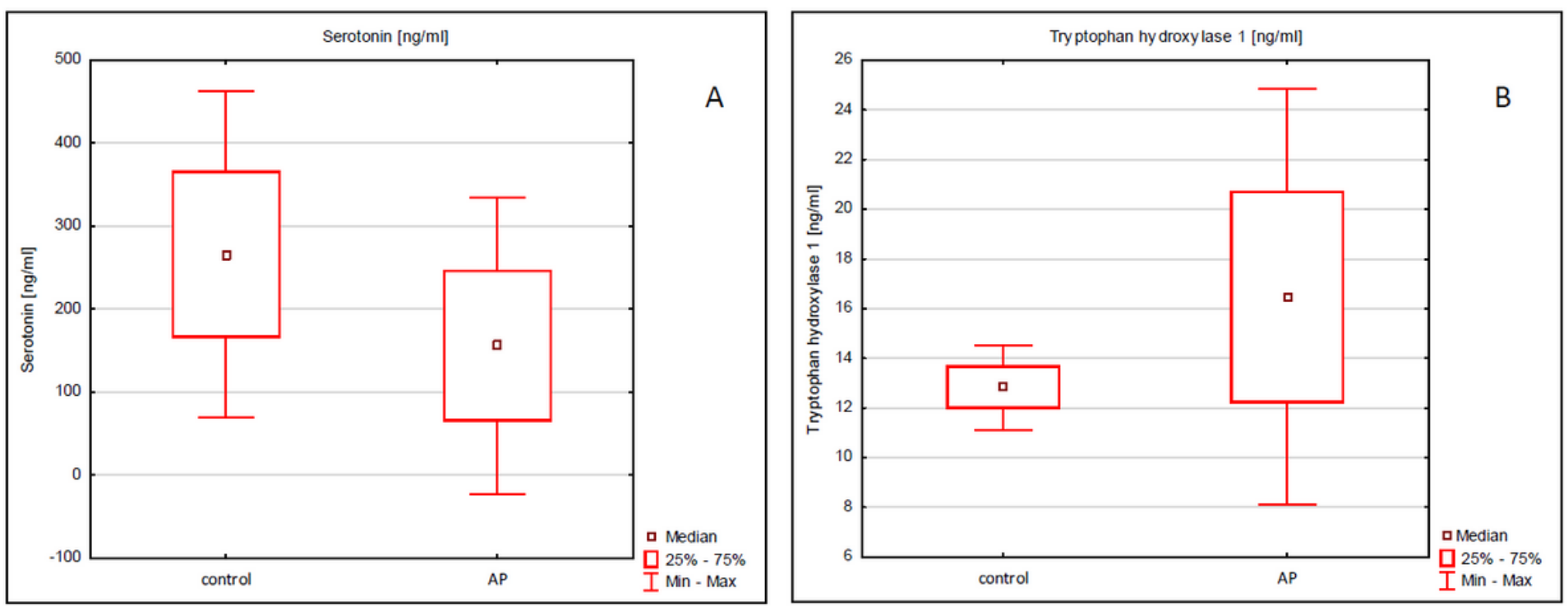
Figure 2

Serotonin (A) and tryptophan hydroxylase 1 (TPH) (B) concentrations in serum (ng/ml) in control and AP groups.
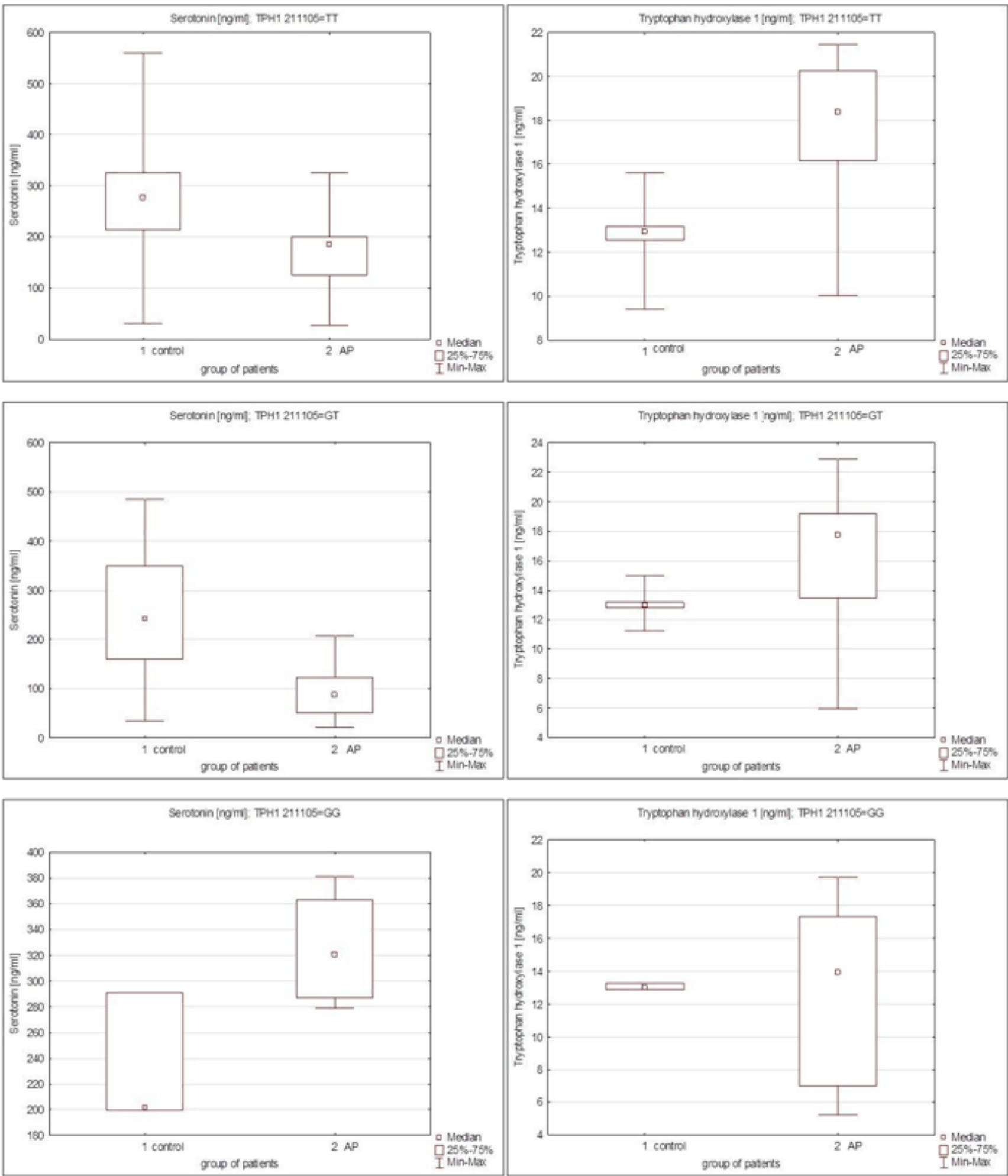

Figure 3 
Serotonin and tryptophan hydroxylase $1(\mathrm{TPH})$ concentrations in serum $(\mathrm{ng} / \mathrm{ml})$ in correlation to TPH rs 211105 TT, GT and GG genotype in control and AP group.

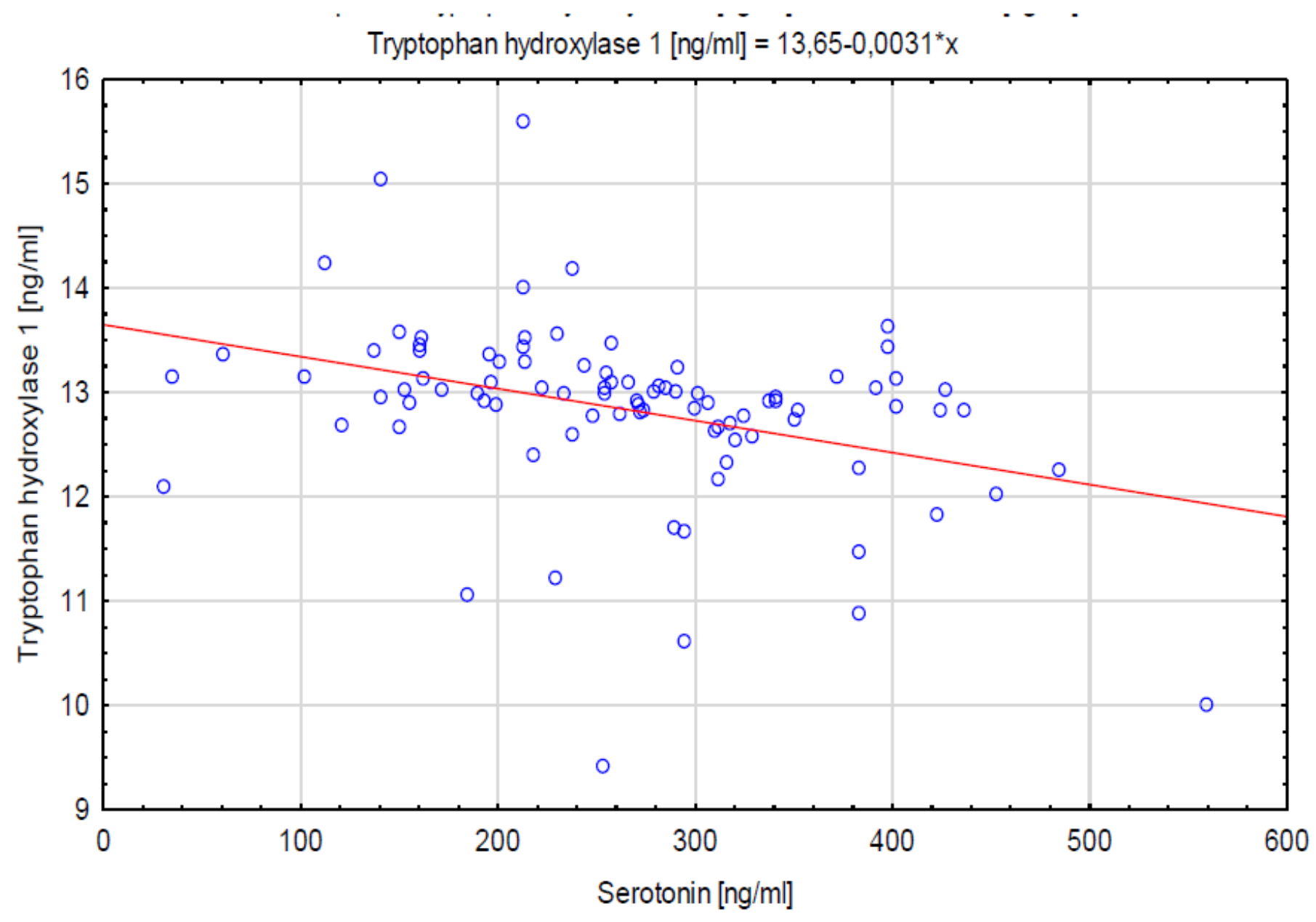

Figure 4

Scatter plot of tryptophan hydroxylase $1[\mathrm{ng} / \mathrm{ml}]$ versus serotonin $[\mathrm{ng} / \mathrm{ml}]$ in control group 
Tryptophan hydroxylase $1[\mathrm{ng} / \mathrm{ml}]=18,9542-0,0159^{*} \mathrm{x}$

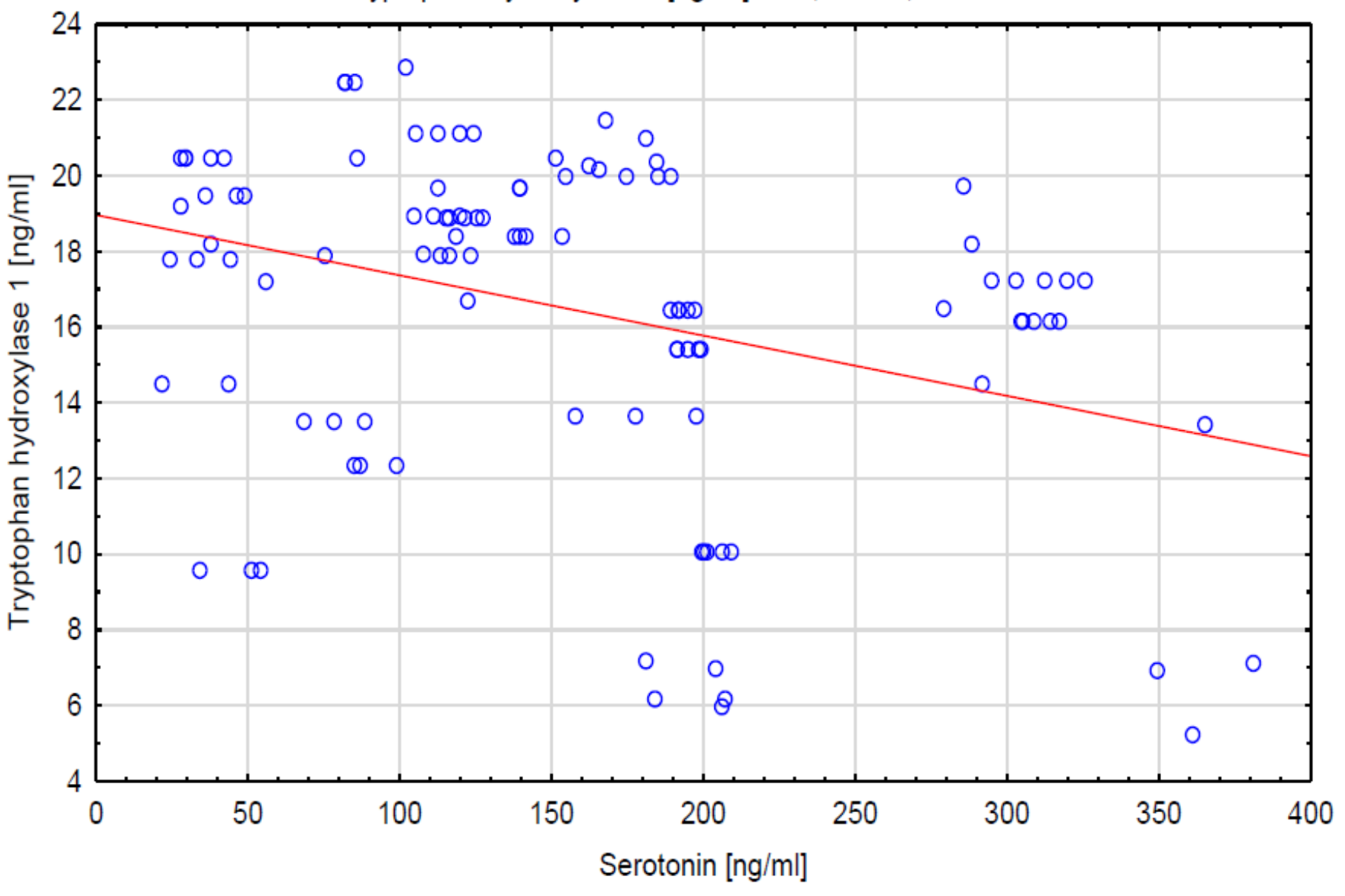

Figure 5

Scatter plot of tryptophan hydroxylase $1[\mathrm{ng} / \mathrm{ml}]$ versus serotonin $[\mathrm{ng} / \mathrm{ml}]$ in AP group 


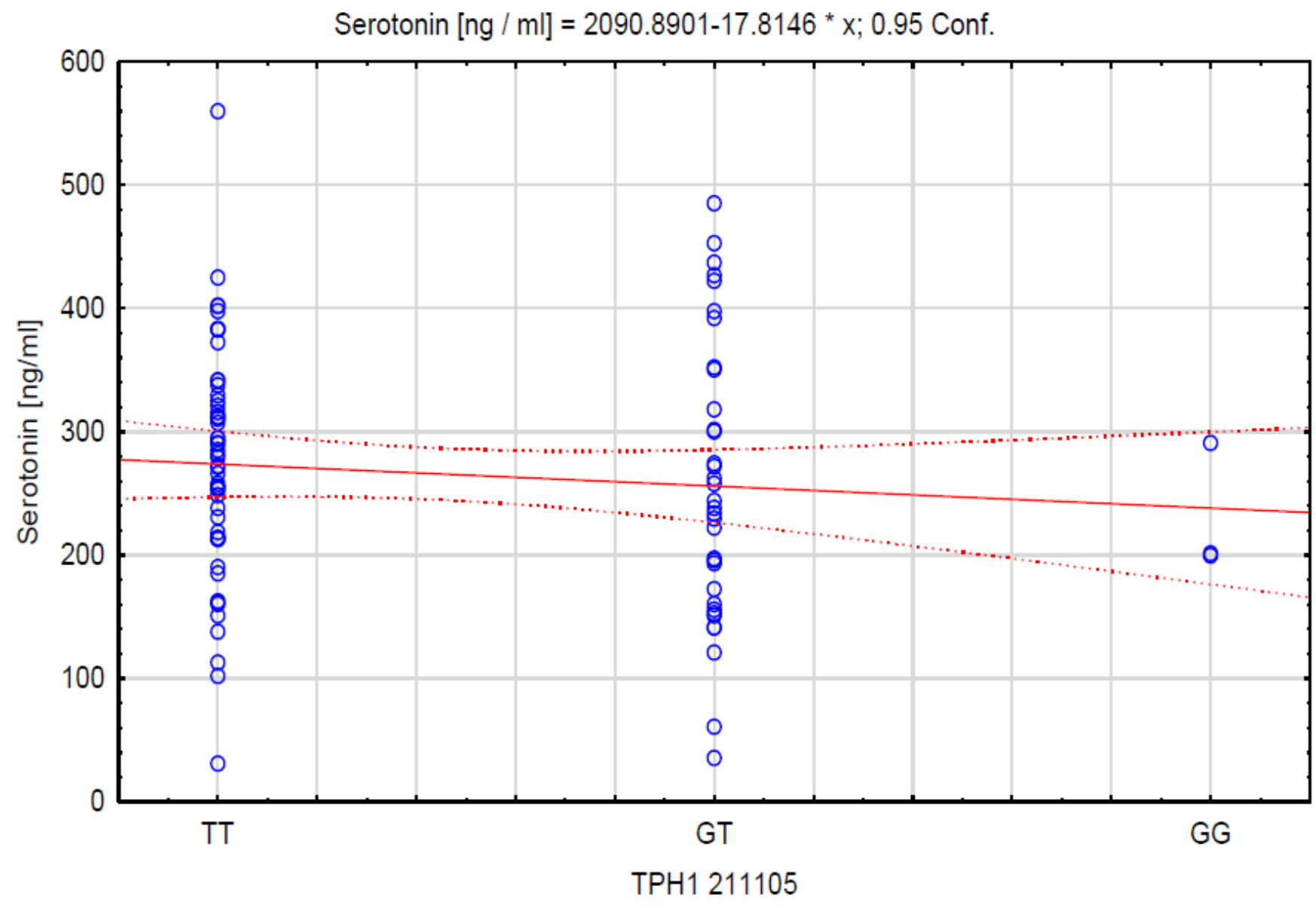

Figure 6

Scatter plot of serotonin [ng/ml] with genotype of rs 211105 in TPH1 gene in control group 


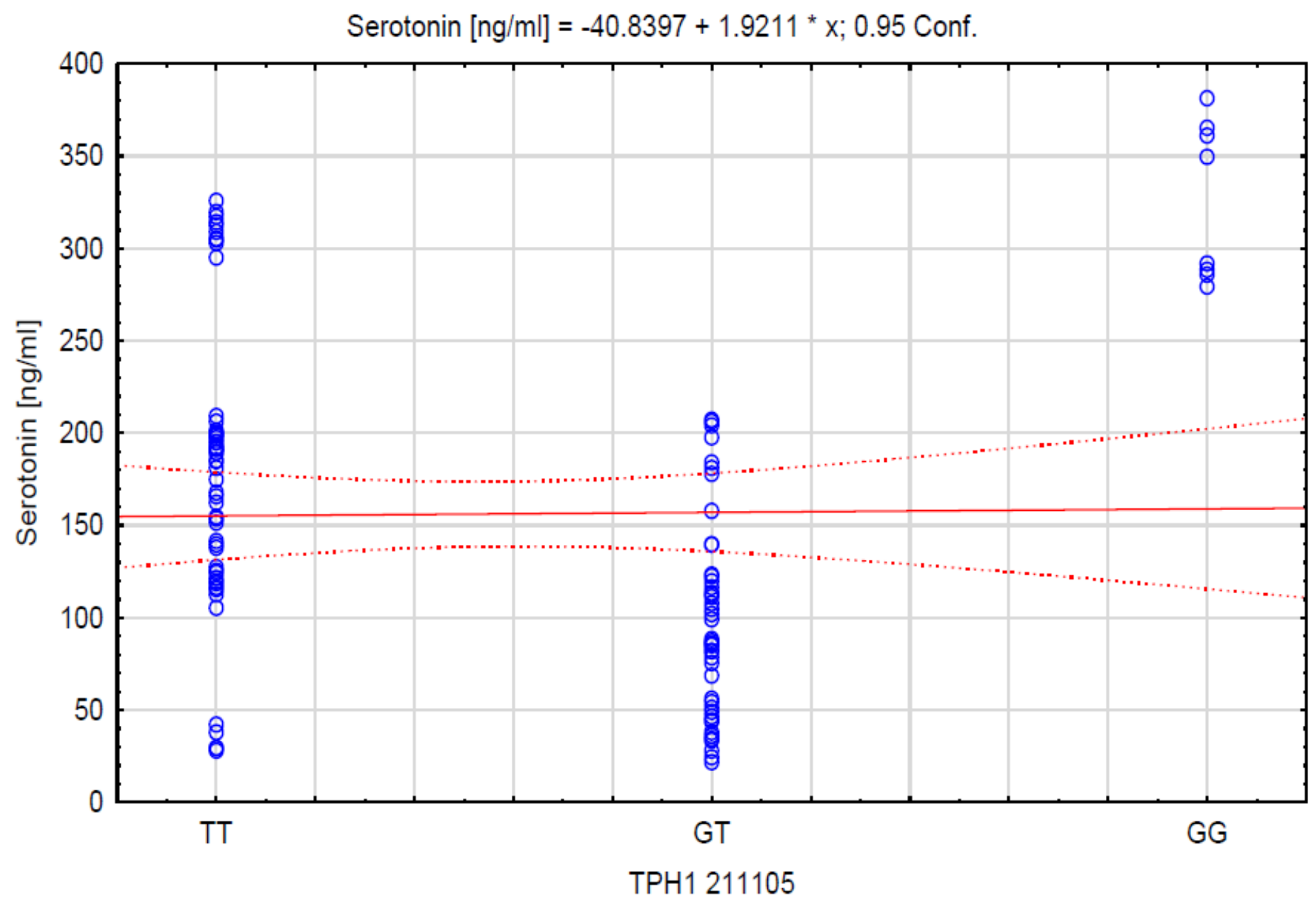

Figure 7

Scatter plot of serotonin [ng/ml] with genotype of rs 211105 in TPH1 gene in AP group 